\title{
Laser surface texturing of polypropylene to increase adhesive bonding
}

Cite as: AIP Conference Proceedings 1960, 060004 (2018); https://doi.org/10.1063/1.5034893

Published Online: 03 May 2018

Chiara Mandolfino, Marco Pizzorni, Enrico Lertora, and Carla Gambaro

\section{ARTICLES YOU MAY BE INTERESTED IN}

Nd:YOV4 laser surface texturing on DLC coating: Effect on morphology, adhesion, and dry wear behavior

AIP Conference Proceedings 1960, 060002 (2018); https://doi.org/10.1063/1.5034891

Ring rotational speed trend analysis by FEM approach in a Ring Rolling process

AIP Conference Proceedings 1960, 040001 (2018); https://doi.org/10.1063/1.5034855

A sectionwise defined model for the material description of $100 \mathrm{Cr} 6$ in the thixotropic state AIP Conference Proceedings 1960, 040006 (2018); https://doi.org/10.1063/1.5034860

\section{Conference Proceedings}

Get $30 \%$ off all

Enter Promotion Code PDF30 at checkout print proceedings! 


\title{
Laser surface texturing of polypropylene to increase adhesive bonding
}

\author{
Chiara Mandolfino a), Marco Pizzorni b) Enrico Lertora ${ }^{\text {c), }}$, Carla Gambaro ${ }^{\text {d) }}$ \\ Department of Mechanical Engineering, Polytechnic School of University of Genoa, Via Opera Pia 15 \\ a) Corresponding author: chiara.mandolfino@unige.it \\ b) marco.pizzorni@hotmail.it \\ c)e.lertora@unige.it \\ d)gambaro@diptem.unige.it
}

\begin{abstract}
In this paper, the main parameters of laser surface texturing of polymeric substrates have been studied. The final aim of the texturing is to increase the performance of bonded joints of grey-pigmented polypropylene substrates. The experimental investigation was carried out starting from the identification of the most effective treatment parameters, in order to achieve a good texture without compromising the characteristics of the bulk material. For each of these parameters, three values were individuated and 27 sets of samples were realised. The surface treatment was analysed and related to the mechanical characteristics of the bonded joints performing lap-shear tests. A statistical analysis in order to find the most influential parameter completed the work.
\end{abstract}

\section{INTRODUCTION}

The demand for and development of polymeric materials has seen exponential growth in recent decades; thanks to their advantages, plastics are increasingly replacing metallic and ceramic materials in many industrial fields, for example electronic, food, automotive and aerospace sectors.

The joining of polymeric materials is certainly one of the key factors that limits or precludes their use in some applications. Many approaches to surface treatments based on both chemical and physical modifications have been developed in recent years in order to improve the surface activity of polymers. Physical methods based on mechanical abrasion are expected to extend bonding area as they increase roughness, but they are not easily automated and sometimes do not provide repeatable results. On the other hand, chemical treatments are typically used with the aim of modifying both the morphology and chemical structure of polymers, but they present serious environmental problems of waste disposal, which has moved investigations to an industrial alternative to these processes.

In this study, the effect of a laser surface pre-treatment on the performance of bonded joints in grey-pigmented polypropylene was examined.

Laser treatment allowed modification of the surface texture of the substrates, in order to increase the frictional forces and contact area between adhesive and surface, similarly to what can be obtained mechanically, for example by sandblasting. The aim of these treatments is to increase the mechanical strength of the joints between polymeric materials that are normally difficult to bond. Furthermore, a laser gives better results in terms of productivity, surface finishing precision, automation and replicability.

The work was carried out starting from a search for the most important treatment parameters, in order to achieve the predetermined goal. For each of these parameters, three values were identified and 27 sets of samples were produced. Surface texturing was analysed and related to the mechanical characteristics of the bonded joints, evaluated using lap-shear tests, in order to determine their shear strength. 


\section{MATERIAL AND METHODS}

The samples were laser textured using an IPG Photonics TRL1904 laser source. The fibre laser maximum power was $50 \mathrm{~W}$ and was used in continuous mode for all of the tests, the wavelength was $1904 \mathrm{~nm}$ and it was installed on a robot arm (Panasonic TA1600). Air was used as a shielding gas in order to protect the optic system. The complete characteristics of the fibre laser system are reported in table 1 .

TABLE 1. Laser system characteristics.

\begin{tabular}{lll}
\hline & \multicolumn{1}{c}{ Fibre laser } & \\
\hline \multicolumn{1}{c}{ Characteristics } & \multicolumn{1}{c}{ Symbol /Value } & Unit \\
\hline Wavelength $\lambda$ & 1904 & $\mathrm{~nm}$ \\
Operating mode & Continuous wave modulation & \\
Nominal maximum power & 50 & $\mathrm{~W}$ \\
Power regulation & $10-100$ & $\%$ \\
Power stability & \pm 1 & $\%$ \\
Beam quality & TEM & \\
Fibre end & Collimator & \\
\hline
\end{tabular}

\section{Materials}

This study was carried out on $2 \mathrm{~mm}$-thick substrates of polypropylene (PP). This polymer is a thermoplastic material without any additive except a colour pigment (carbon black).

Sample sizes $(100 \times 25 \times 2 \mathrm{~mm})$, overlap area $(25 \times 12.5 \mathrm{~mm})$ and bonding procedure were set according to ASTM D3163 standard (Fig. 1).

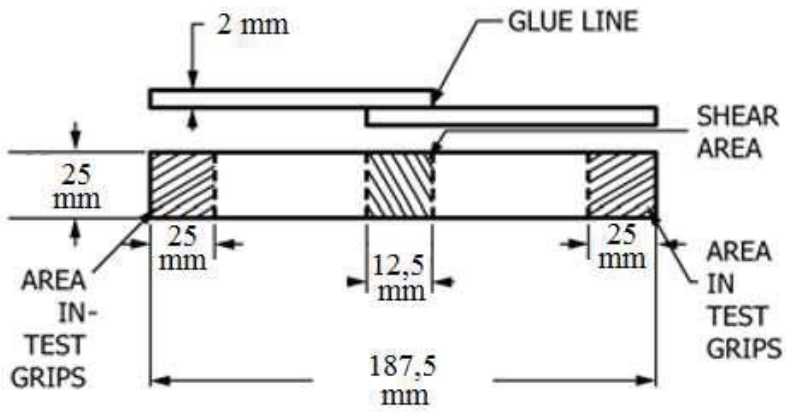

FIGURE 1. Samples size.

After the laser treatments, the surface of the samples was cleaned by acetone degreasing in order to remove the dirt and oil.

For the production of the joint 3M Scotch Weld DP490 adhesive was used; it is a bicomponent thixotropic structural adhesive.

The base is epoxy and has a pasty consistency; the colour is black. The accelerant is amine, which has a white colour. The mixing ratio is $2: 1$.

Its main features are:

- two possible cure cycles can be used: 7 days at $23^{\circ} \mathrm{C}$ or alternatively 1 day at $23^{\circ} \mathrm{C}$ and 1 hour at $80^{\circ} \mathrm{C}$; in this case the room temperature was adopted in order not to compromise the polymer characteristics;

- $\quad$ work life $\left(23^{\circ} \mathrm{C}\right)$ of approximately $180 \mathrm{~min}$;

- $\quad$ storage temperature $25^{\circ} \mathrm{C}$ or lower.

This kind of adhesive shows a relatively good adhesion on the polymeric surfaces. Adhesives with superior shear strength were not considered as the substrates would break and the effect of the surface treatment of the pieces could not be assessed. 


\section{Experimental procedure}

The transition of a laser radiation on the surface of thermoplastic polymeric materials allows its remodelling and this effect is exploited in order to increase the roughness and the real area on which the adhesive will interact with the substrate.

Three parameters were kept fixed for all the tests. The first one was the path of the laser head: in this case, a simple straight and parallel path was adopted. It creates a superficial roughness with periodic trend and grooves in a direction perpendicular to the direction of the force to which the joints will be subjected during the tensile tests. This is the simplest possible configuration and therefore easily replicable on a large scale; the effects are an increase of the real surface and of the frictional forces in the direction in which the joints will be tested.

The second one is the air pressure at the outlet of the laser head, which has no significant influence and its value was fixed at 2 bars. The travel speed of laser source was fixed at the value of $2 \mathrm{~m} / \mathrm{min}$.

Once the main configuration had been decided, mainly three parameters were considered:

- focus of the laser beam (D);

- $\quad$ output power of the laser source $(\mathrm{P})$;

- $\quad$ distance between one pass and another (s);

Figure 2 reports a schematic representation of the surface texturing procedure and some of the main parameters designation.

Some variation of the distance between the surface and the laser focal lens with respect to the optimal distance ( $40 \mathrm{~mm}$ is the distance in which the spot is minimum) were adopted, assuming to treat larger surfaces with less heat input and therefore realise fewer deforming effects.

Regarding power "P" and speed "v", a close link between these two variables was immediately established. In principle, keeping the other parameters fixed, equal $\mathrm{P} / \mathrm{v}$ ratios lead to equal surface effects.

In fact, the thermal energy " $E$ " absorbed by the material is the product of the power and the time " $\mathrm{t}$ " $(\mathrm{E}=\mathrm{P} \times \mathrm{t})$, the speed is the ratio between the space "l" travelled by the passes of the laser beam and the time $(\mathrm{v}=1 / \mathrm{t})$; as a consequence, $\mathrm{E}=(\mathrm{P} / \mathrm{v}) \times 1$. The space travelled with the same configuration of the path is constant; therefore, the energy absorbed by the surface is equal for each $\mathrm{P} / \mathrm{v}$ ratio.

To study the texturing effects, we can also theorise a thermal energy per unit area $\left[\mathrm{E}_{\mathrm{A}}=\mathrm{E} / \mathrm{A}=\mathrm{P} /(\mathrm{v} \times \mathrm{s})\right]$. From first experimental tests we observed that $\mathrm{P} /(\mathrm{v} \times \mathrm{s})$ ratios lower than $0.5 \mathrm{~J} / \mathrm{mm}^{2}$ were not very incisive; those greater than $1.2 \mathrm{~J} / \mathrm{mm}^{2}$ led to too pronounced deformation effects.

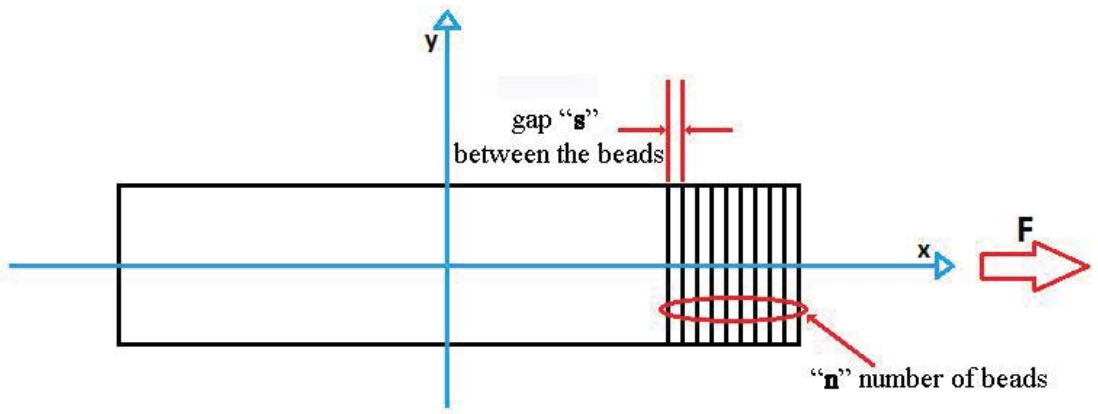

FIGURE 2. Schematic representation of the surface texturing procedure.

The gap between two passes (s) substantially changes the surface geometry of the samples, so some preliminary tests were conducted in order to measure the width of the single pass and realise those that cover the entire bonding area.

Measurements by microscope and by profilometer also detected the exact shape of the roughness caused by the passage of the laser crossing (Fig. 3a), depending on the concentration of energy; and in particular:

- the "flattening" of micro asperities initially present on the samples;

- the semi-circular swelling of the area affected by the laser beam;

- the formation of a valley in the top area of the swelling (Fig. 3b);

- the depth of the groove inside the plastic material. 


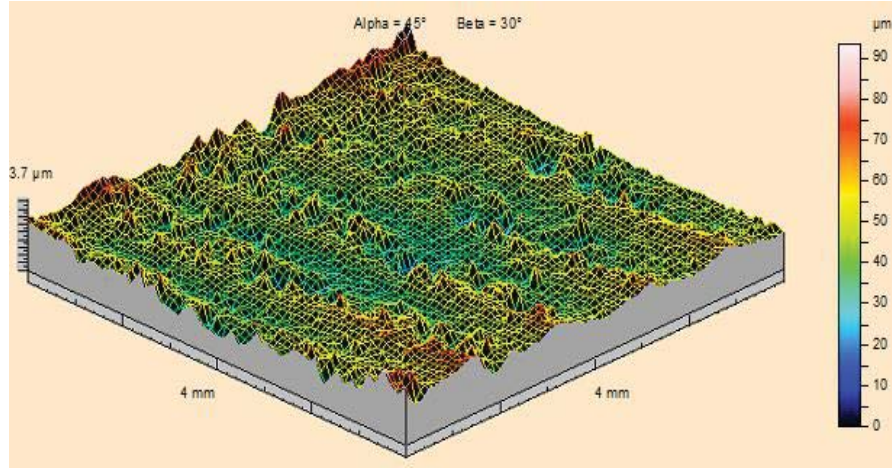

(a)

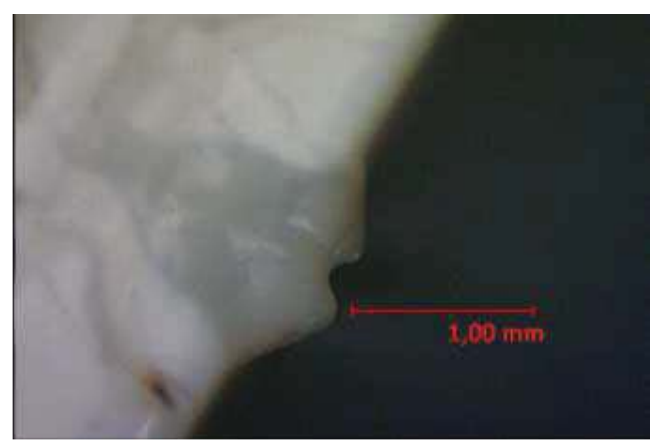

(b)

FIGURE 3. Detection of the groove geometry using profilometer (a) and laser surface texturing observed by optical microscope photography (b)

After the first preliminary investigation, the effect of three parameters were investigated, using three values for each parameter and all their combinations. In table 2 a summary of the laser texturing final parameters is reported.

TABLE 2. Set-up parameter used for laser texturing of polypropylene

\begin{tabular}{ccc}
\hline Output Power $\mathbf{P}[\mathbf{W}]$ & Focal distance $\mathbf{D}[\mathbf{m m}]$ & Gap between two passes s [mm] \\
\hline 30 & 40 & 0.6 \\
40 & 50 & 0.9 \\
50 & 60 & 1.2 \\
\hline
\end{tabular}

In all, 27 series of 5 bonded samples were realised. In order to have a complete comparison, a large parameter case series was adopted, in fact:

$\cdot \mathrm{P} /(\mathrm{v} \times \mathrm{s})$ ratios go beyond the aforementioned boundaries of 0.5 and $1.2 \mathrm{~J} / \mathrm{mm}^{2}$;

- grooves created by the laser beam form an amplitude that is not sufficient to cover the entire bonding surface, to the other extreme in which they overlap each other.

The samples were mechanically characterised using a lap shear test, following ASTM D3163 standard and a test speed of $1.3 \mathrm{~mm} / \mathrm{min}$.

\section{RESULTS AND DISCUSSION}

After realisation of the joints, the mechanical characterisation was conducted through a lap-shear test. The abbreviations used hereafter indicate the combination of the parameters adopted for that treatment: $\mathrm{s} x \mathrm{x} \_\mathrm{D}$ yy_P zz (for example s06D40P30 means: gap between the passes of $0.6 \mathrm{~mm}$, focal distance D of $40 \mathrm{~mm}$, power of $30 \mathrm{~W}$ ). A series of only degreased without laser treatments was also produced and tested.

Before proceeding with the joining of two treated samples, a visual investigation was carried out with the aid of an optical microscope. Through this analysis, it was possible to observe the influence of the parameters on the surface finish.

As expected:

- treatments with a $\mathrm{P} /(\mathrm{v} \times \mathrm{s})$ too high (in particular the s06DyyP50 series characterised by the highest value, equal to $1.25 \mathrm{~J} / \mathrm{mm}^{2}$ ) have consistently damaged the samples, either by bending them or by generating anomalous bulges on the surface;

- treatments with a $\mathrm{P} /(\mathrm{v} \times \mathrm{s})$ at the lower limits of the tested range (in particular the s12DyyP30 series characterised by the value of $0.375 \mathrm{~J} / \mathrm{mm}^{2}$ ) had a very mild superficial modelling, with a coverage of the treated surface less than $50 \%$ of the total area.

Analysing the load-displacement curves (Fig.4) related to the various treatments immediate considerations of considerable interest can be drawn: 
- samples with mild treatments $\left(\mathrm{P} /(\mathrm{v} \times \mathrm{s})<0.5 \mathrm{~J} / \mathrm{mm}^{2}\right)$ had lower performance in terms of bonding strength (Fig.4a);

- samples that received too much energy $\left(\mathrm{P} /(\mathrm{v} \times \mathrm{s})>1.2 \mathrm{~J} / \mathrm{mm}^{2}\right)$ underwent uncontrolled deformations and were characterised by a high dispersion as well as a low average strength (Fig.4b);

- samples submitted to treatments with a properly calibrated energy supply had a deeper texturing, without producing unwanted deformations. They had the best performance as well as less dispersion of the results (Fig.4c).

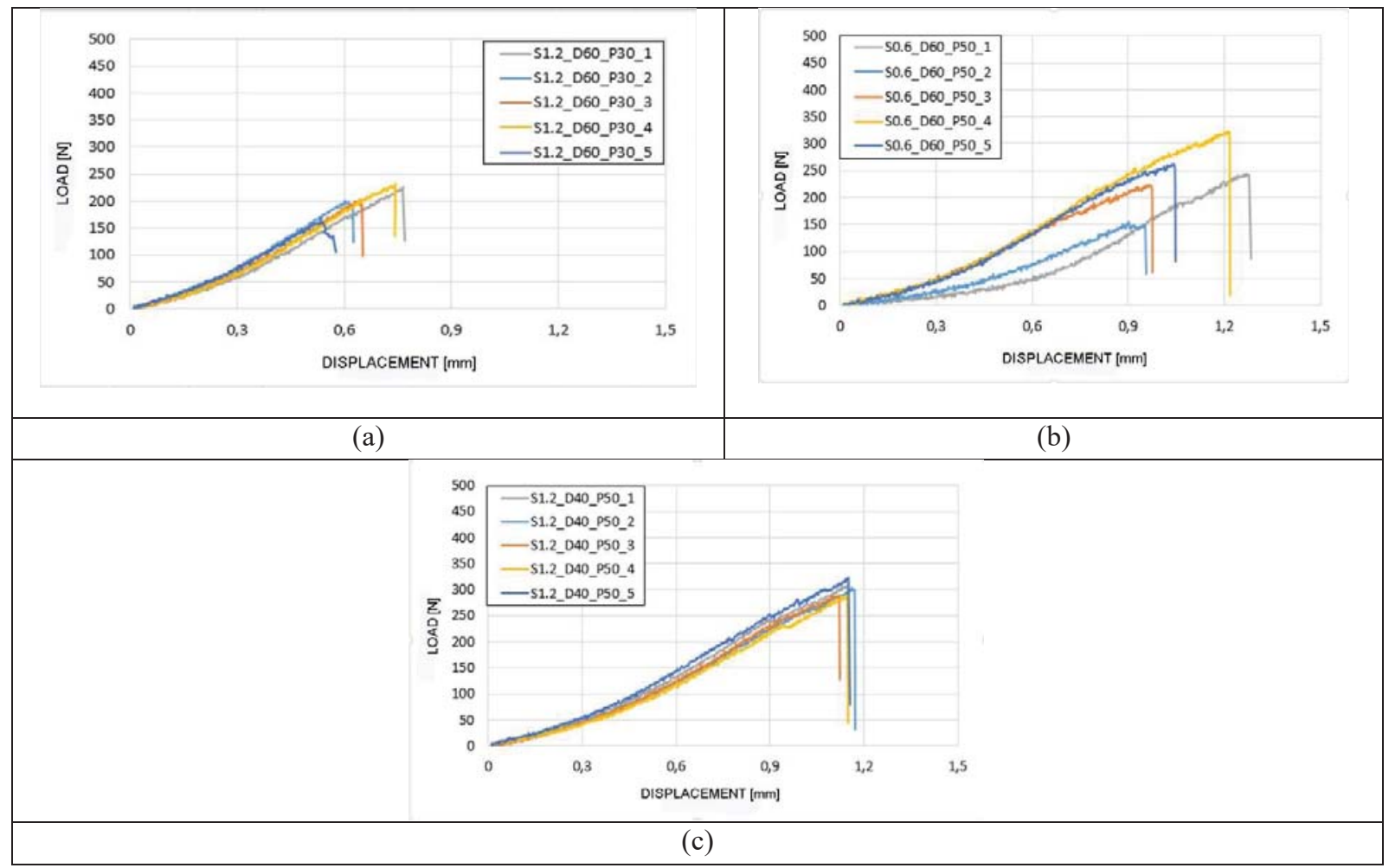

FIGURE 4. Comparison between Load-Displacement curves for samples with mild treatments (a) samples "over treated" (b) and samples treated with correct energy

Figure 5 shows the histograms that summarise all the tests performed; the shear strengths of the joints are shown at the varying of the set-up parameters. Y-axis reports the average strength of the series of treated samples and the relative standard deviation.

In order to understand the effect of each parameter on the mechanical properties of the bonded joints, Pearson correlation coefficients were calculated for the test series and the results are reported in table 3 .

TABLE 3. Correlation coefficient.

\begin{tabular}{cc}
\hline Control factors & \\
\hline Output power $[\mathrm{W}]$ & 0.336 \\
Focal distance $[\mathrm{mm}]$ & -0.733 \\
Gap between passes $[\mathrm{mm}]$ & -0.093 \\
\hline
\end{tabular}

The coefficient demonstrates that all the three parameters are proportional to the maximum force obtained from the lap shear tests. Focal distance was the most significant and in particular is quite strongly inversely proportional. 
Output power, related to energy, is also significant while the gap between the passes seems to be not so significant, at least in this range of values.

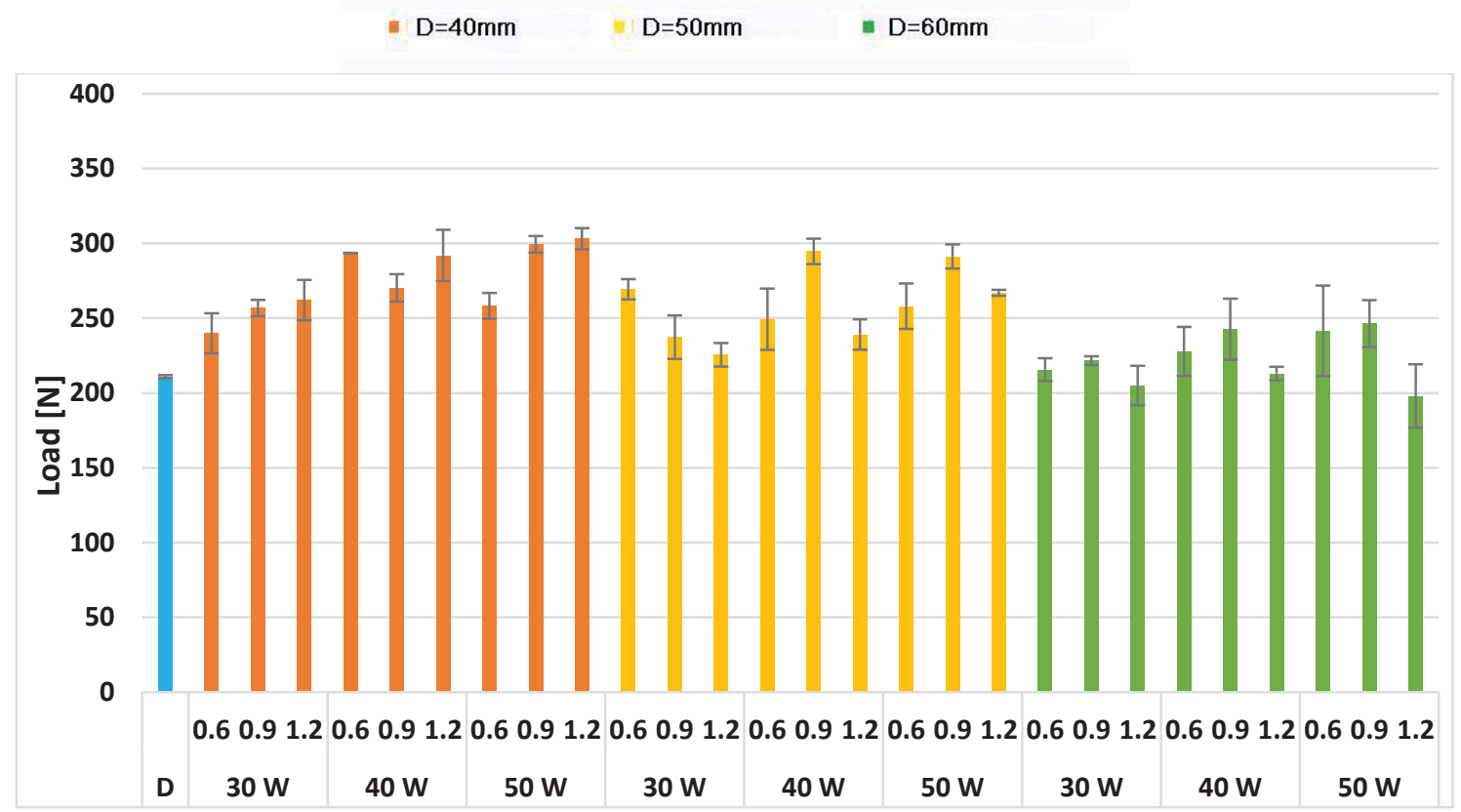

FIGURE 5. Summary results of the mechanical characterisation

\section{CONCLUSION}

Analysing these results, the following conclusions can be drawn:

- defocus has only negative effects on the success of the treatment: the greater the distance is compared to the focus, the smaller the strength of the joints is, increasing the dispersion of the results;

- as regards the power of the source, with "s" equal to $0.6 \mathrm{~mm}$ the power that is most performing is the intermediate between the three values tested, with the other values of "s" the best treatments were those with the maximum power available;

- the distance between the passes is not very significant considering the effect on the shear strength.

\section{REFERENCES}

1. E.M. Petrie, Handbook of Adhesives and Sealants, (McGraw-Hill, USA, 2000).

2. A. Baldan, J. Mater. Science 39, 1- 49 (2004).

3. ASTM D2093 - 03. Standard Practice for Preparation of Surfaces of Plastics Prior to Adhesive Bonding, 2003.

4. ASTM D3163 - 01. Standard Test Method for Determining Strength of Adhesively Bonded Rigid Plastic Lap-Shear Joints in Shear by Tension Loading, 2008.

5. C. Leone, S. Genna, A. Caggiano, Compact disc laser cleaning for polycarbonate recovering, Procedia CIRP, 2013; 9, 73-78.

6. C. Mandolfino, E. Lertora, S. Genna, C. Leone, C. Gambaro, Procedia CIRP 33, 458-463 (2015).

7. C. Mandolfino, D. Brabazon, É. McCarthy, E. Lertora, C. Gambaro, I.U. Ahad, "Laser welding of polypropylene using two different sources" in 20th International ESAFORM Conference on Material Forming, ESAFORM 2017, AIP Conference Proceedings 1896, edited by D. Brabazon et al. (American Institute of Physics, Melville, NY, 2017), Article number 180002. 